affect the biodiversity and long-term survival of ecosystems. He has studied the impact of subsistence and commercial hunting on tropical forest ecosystems, and the social and economic changes associated with declines in the abundance of wildlife.

We welcome them all and look forward to working with them to guide Oryx into the next century.

The issues of whaling and the potential resumption of a limited trade in ivory from three African countries, which were covered in recent issues of Oryx resulted in several let- ters to the editor. Some of these are published in this issue. Oryx welcomes letters but readers wishing to contribute their views for consideration for publication in News and Views are asked to keep letters as concise as possible. The editor reserves the right to edit long letters (more than 750 words).

Contributions are also welcomed for Briefly. Short items of news should be sent to Catharine Baden-Daintree at the FFI office in Cambridge.

\title{
GUESTEDITORIAL
}

\section{Changing conservation aims - who will represent wildlife?}

Times certainly change. Even campaigning for wildlife conservation has become increasingly complex and confused. Some two decades ago, wildlife campaigns were readily accepted as beneficial to the 'environment' and, hence, ultimately in the best interests of our own species. We accepted the idea that the protection of keystone species - notably large, wideranging mammals such as elephants and whales - required the protection of their habitat and that this would contribute to the conservation of a much wider range of species. (This may also help explain the focus over the years of Oryx on mammals.) At the same time there was also early recognition that the local human dimension needed to be taken into account. However, we now also know about the existence of profound global-scale threats, particularly climate change but also the ubiquitous, persistent environmental contaminants that now taint all living things. To some extent this new knowledge may help to explain why modern environmental strategies have come to focus on 'the maintenance of biodiversity' and 'sustainable use'.

Change is not always for the better. Wildlife campaigners are increasingly painted as selfseeking, non-scientific misanthropists who are incapable of seeing the 'bigger picture'. Such rhetoric has helped to splinter the conservation community, with the environmental lobby (focused on urgent global threats) and the animal welfare lobby (focused on the welfare of wildlife) at different ends of a spectrum. Yet the common ground between these interests remains enormous. Environmentalists are now increasingly shy of expressing a fondness for wildlife or concern for welfare matters. Such sentiments are not scientific in a world where what is interpreted as science now provides the most important conservation doctrine.

It is also notable that the term 'natural resource management' is increasingly replacing the word 'conservation'. Changes in terminology underline changes in aims and approaches. Why, for another example, has 'sustainable use' displaced 'stepping lightly on the Earth' or its more modern form, the 'precautionary approach'? The cynical might simply note that the first is supported by the more powerful lobby, ranging from multinationals to those local communities that are still inextricably linked to local natural resources. The common interest within this spectrum is a wish not to see their resource use inhibited 'unduly'.

However, is our knowledge of planetary systems really so good that 'sustainable use' should replace precaution as our guiding principle, especially as an actual direction to 'use' in response to human 'needs' seems to be 
becoming part of our international guiding paradigm? Does not the threat of global changes and the recognition of other long-term damage mean that we have a greater responsibility to be more protective of our wildlife?

Increasingly, the world resembles a giant court room where 'needs' are measured and weighed, and interests have their representation. It was popular at one time to talk about being advocates for the mute - those that could not speak for themselves; this remains an important role. However, those that once spoke exclusively for animalkind now often try to balance this by giving consideration to important human users. This may often be appropriate but it may also stop them from being as effective as advocates for wildlife. In court, representation strives to be fair, but legal representatives normally only work on behalf of one interest.

In the environmental 'trials' yet to come, decisions will also have to be made about what status is to be given to wildlife. Elephants provide a recent example. They are among those species traditionally identified as deserving of the fullest protection. The reopening of the trade in ivory may now provide a test case for conflicting philosophies, at no small risk to the species involved. Many of us now fear that their 'use' cannot be adequately controlled. As long as there is sufficient money to be made, not only will individual elephants suffer but conservation at regional, or even world, level may be threatened. The world is not ready to control such matters, appropriate or otherwise.

Conservationists and other policy makers need to be reminded, perhaps, that while global-scale problems are indeed urgent, other factors are also affecting wildlife (or, if you prefer, biodiversity). In the late 1980s, when the threat of climate change started to receive mainstream scientific support, we should have realized that we now needed to work at both a planetary level and on a finer scale. Instead, it might be suggested that the finer scale of wildlife conservation is being increasingly abdicated and handed back to the user groups.

Not only do 'needs' require weighing in our hypothetical global court but so do 'rights'. Do, for example, the rights of Norwegian whalers to make a profit from their chosen trade outweigh the rights of other people in the same region to enjoy the presence of local populations of healthy, friendly and numerous whales in their waters or, indeed, the rights of the whales themselves? Here are two contentious issues about wildlife use that are currently being buried by the rushed (and increasingly sophisticated) moves to use them. First, what kind of wildlife populations do we want? Traditionally, conservation is focused on species conservation and activities are most intense for the most threatened. However, perhaps we also want to see creatures present in quantities approaching historical levels or the environment's carrying capacity. Take, for example, the case of the European harbour porpoise. Unlike the closely related vaquita, this porpoise has a widespread distribution and no one would argue that it is as threatened with extinction. However, it has been effectively removed from parts of its European range (the Mediterranean, Baltic and some waters around the UK), thus depriving many people of the pleasure of encountering it.

Second come animal rights, which I will not discuss at length here (although a growing body of literature is available). However, it does seem to be part of our evolution to gradually recognize such rights. Historically this has applied to sections of our own society but is not acknowledgement of the 'alien' intelligences around us a further sensible step, even if it does inhibit some of our activities?

In the past I have felt that there was an inevitability about this recognition and awarding of such rights. The question was not 'if' but 'when'. Now, however, peering towards the next century, I wonder if we are a species too self-focused to see what I interpret as the 'wider picture'. The biggest threat to wildlife and biodiversity may not be what proportion (if any) can be 'safely' removed, but how we view them. In particular, are animals a resource or something more?

Mark Simmonds

Whale \& Dolphin Society

Alexander House

James Street West, Bath BA1 2BT, UK 